\title{
Potential of Citrus junos Fruit Waste From the Food Processing Industry for Weed Management
}

\author{
Hisashi Kato-Noguchi ${ }^{1}$ and Yukitoshi Tanaka \\ Department of Applied Biological Science, Faculty of Agriculture, Kagawa \\ University, Miki, Kagawa 761-0795, Japan
}

Additional index words. allelopathy, Citrus junos, growth inhibition, phytotoxicity, weed management

\begin{abstract}
The allelopathic potential of Citrus junos Tanaka waste from food processing industry after juice extraction was investigated under laboratory conditions. $C$. junos waste powder inhibited the growth of roots and shoots of alfalfa (Medicago sativa L.), cress (Lepidium sativum L.), lettuce (Lactuca sativa L.), crabgrass (Digitaria sanguinalis L.), timothy (Phleum pratense L.) and ryegrass (Lolium multiflorum Lam.). Significant reductions in the growth of roots and shoots were observed as the powder concentration increased. The concentration of abscisic acid- $\beta$-D-glucopyranosyl ester (ABA-GE) in $C$. junos waste was determined to be $17.9 \mathrm{mg} \cdot \mathrm{kg}^{-1}$ dry weight. Its concentration in $C$. junos waste appears to account mostly for the observed inhibition of tested plant seedlings. These results indicate that $C$. junos waste is allelopathic with potential for use in agriculture to suppress weed emergence, which should be investigated further in the field.
\end{abstract}

Citrus junos is one of the major citrus in Japan. The fruit is processed into juice and is often preferred to vinegar as an ingredient in sauces and salad dressings for its special flavor. After juice extraction, the fruit pulp is currently discarded as waste. The disposal of food processing wastes is expensive and is becoming a serious environmental issue. It seems, therefore, worthwhile to discover beneficial uses for $C$. junos waste.

Citrus fruits contain a variety of biologically active compounds, including terpenoids and flavonoids (Davies, 2000; Iwase et al., 2000; Ogata et al., 2000; Uchiyama et al., 2004). It was also found that an aqueous methanol extract of $C$. junos fruit peel inhibited growth of several plant species, including weed species (Fujihara and Shimizu, 2003). The compound causing the inhibitory effect of the aqueous methanol extract of $C$. junos fruit peel was isolated and identified as abscisic acid- $\beta$-D-glucopyranosyl ester (ABA-GE; Kato-Noguchi et al., 2002). These findings suggest that $C$. junos peel possesses potent allelopathic activity and the peel may be effective as a weed suppressive agent. In this study, the allelopathic potential of $C$. junos waste was determined under laboratory conditions.

\section{Materials and Methods}

Material. The fruit waste (peel and pulp) of Citrus junos after juice extraction was obtained from a local food processing com-

\footnotetext{
Received for publication 18 Apr. 2006. Accepted for publication 28 May 2006.

${ }^{1}$ To whom reprint requests should be addressed; e-mail hisashi@ag.kagawa-u.ac.jp
}

Table 1. $\mathrm{I}_{50}$ of $C$. junos waste powder for root and shoot growth of test plants. ${ }^{\mathrm{z}}$

\begin{tabular}{lcc}
\hline & \multicolumn{2}{l}{$\mathrm{I}_{50}(\mathrm{mg}$ powder per Petri dish $)$} \\
\cline { 2 - 3 } Test Species & Root & Shoot \\
\hline Alfalfa & $1.01 \pm 0.09$ & $0.93 \pm 0.06$ \\
Cress & $0.57 \pm 0.05$ & $0.65 \pm 0.05$ \\
Lettuce & $0.83 \pm 0.07$ & $1.21 \pm 0.08$ \\
Timothy & $0.44 \pm 0.04$ & $0.53 \pm 0.04$ \\
Ryegrass & $1.95 \pm 0.17$ & $1.82 \pm 0.16$ \\
Crabgrass & $0.72 \pm 0.05$ & $1.41 \pm 0.12$ \\
\hline
\end{tabular}

${ }^{\mathrm{z}_{50}}$ value in each bioassay was determined by a logistic regression analysis as described in the text and expressed mg dry weight powder per Petri dish. Means \pm SE from five independent experiments with 10 plants for each determination are shown.

waste powder in the bioassay was $0,0.1,0.3$, 1,3 , and $10 \mathrm{mg}$ per Petri dish.

Seeds of the test species were allowed to germinate on filter paper (No. 2, Toyo, Japan) in the dark at $25^{\circ} \mathrm{C}$ for 1 to $3 \mathrm{~d}$. Ten germinated seeds of each species were then arranged on the surface of sand in each Petri dish. Seedlings were then incubated in the dark at $25{ }^{\circ} \mathrm{C}$ for $48 \mathrm{~h}$, and shoot and root length of each seedling was measured. These lengths were expressed as a percentage of the root and shoot length of control seedlings grown on moistened quartz sand in absence of the C. junos powder. The experiment was repeated five times with 10 plants for each determination.

Quantification of $A B A-G E$. The powder of $C$. junos fruit waste was extracted with methanol and concentration of ABA-GE in the extraction was determined using highperformance liquid chromatography according to the procedure described by Kato-Noguchi et al. (2002). The experiment was repeated three times with four assays for each determination.
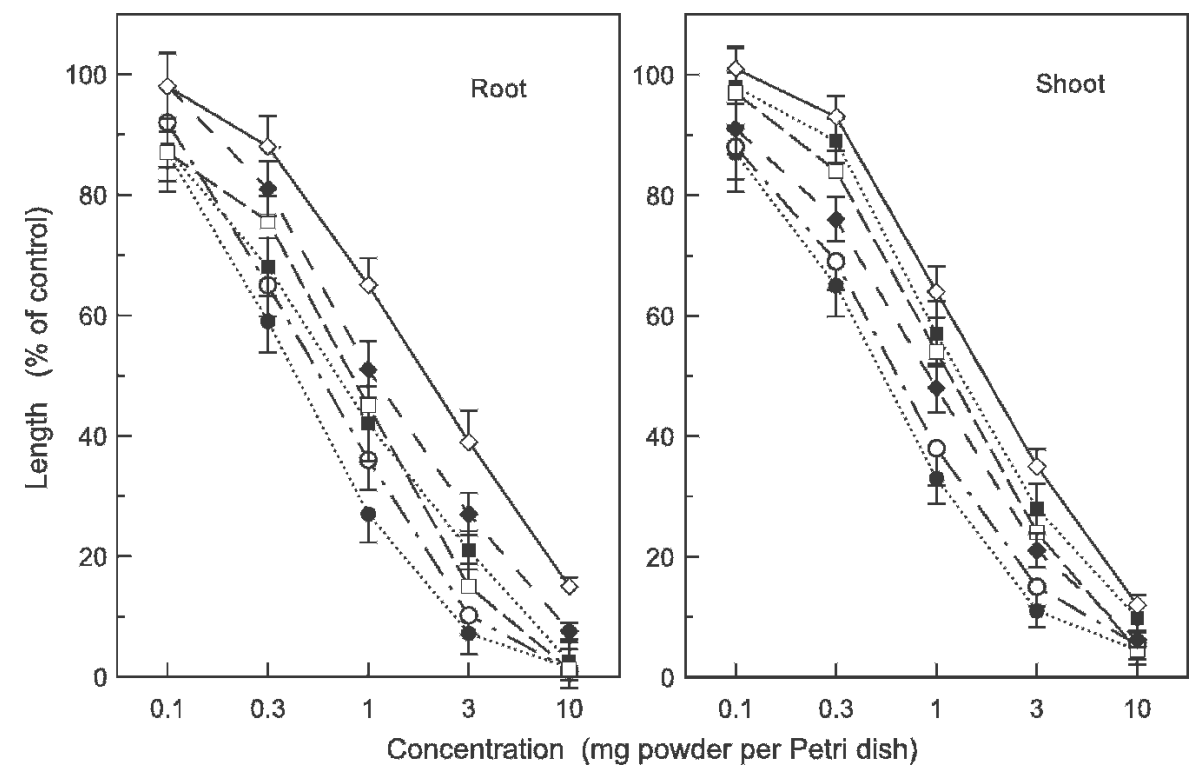

Fig. 1. Effects of powder of C. junos waste on the growth of roots and shoots of timothy $(\bullet)$, cress $(\bigcirc)$, crabgrass $(\square)$, lettuce $(\square)$, alfalfa $(\diamond)$, and ryegrass $(\diamond)$. Root and shoot length was determined after $48 \mathrm{~h}$ of incubation in the dark at $25^{\circ} \mathrm{C}$. Means $\pm \mathrm{SE}$ from five independent experiments with 10 plants for each determination are shown. 


\section{Results and Discussion}

Citrus junos powder suppressed the growth of six test plants at concentrations greater than 0.1 to $0.3 \mathrm{mg}$ per Petri dish for roots and shoots (Fig. 1). Increasing the concentrations increased the inhibition of the root and shoot growth of all test plant species, although its effectiveness differed with species. The concentrations required for $50 \%$ inhibition in the assay (defined $\mathrm{I}_{50}$ ) were determined by a logistic regression analysis (Table 1). Comparing $\mathrm{I}_{50}$ values, the effectiveness of the powder was the greatest in timothy and the least in rye grass. These results suggest that $C$. junos waste possesses allelopathic activity and may work as a plantinhibiting agent.

The concentration of ABA-GE in C. junos waste powder was determined to be $17.9 \mathrm{mg}$ $\mathrm{kg}^{-1}$ dry weight $(42 \mu \mathrm{mol})$. At concentrations greater than $0.3 \mu \mathrm{M}, \mathrm{ABA}-\mathrm{GE}$ inhibited the growth of the lettuce shoots and roots (Kato-Noguchi et al., 2002). Thus, ABAGE concentration in $C$. junos waste appears to account mostly for the observed inhibition of tested plant seedlings. In addition, other potentially inhibitory compounds might be in the $C$. junos waste powder (Kato-Noguchi et al., 2002).

Many investigations have attempted to exploit allelopathy of plants for weed control purposes in a variety of agricultural settings
(Duke et al., 2000; Inderjit, 1996; Seigler, 1996). Synthetic chemical herbicides may continue to be a key component in most integrated weed management systems, but controlling weeds through allelopathy is one strategy to reduce herbicide dependency (Duke et al., 2000; Einhellig, 1996; Putnam, 1988; Weston, 1996). The present research suggests that $C$. junos waste powder may be potentially useful for weed management in an agricultural field setting, which should be investigated further in the field for practical application of the powder. There may be the potential benefits of turning a previously useless waste product into a valuable soil amendment and improving the economics of the food processing industry.

\section{Literature Cited}

Davies, K.M. 2000. Plant color and fragrance. In: R. Verpoorte, and A.W. Alfermann (eds.), Metabolic Engineering of Plant Secondary Metabolism. Kluwer Academic Publishers Dordrecht. p. 127-163.

Duke, S.O., F.E. Dayan, J.G. Romagni, and A.M. Rimando. 2000. Natural products as sources of herbicide, current status and future trends. Weed Res. 40:99-111.

Einhellig, F.A. 1996. Interactions involving allelopathy in cropping systems. Agron. J. 88:886-893.

Fujihara, S. and T. Shimizu. 2003. Growth inhibitory effect of peel extract from Citrus junos. Plant Grow. Regul. 39:223-233.
Inderjit. 1996. Plant phenolics in allelopathy. Bot. Rev. 62:186-202.

Iwase, Y., Y. Takemura, M. Ju-ichi, C. Ito, H. Furukawa, S. Kawaii, M. Yano, X.Y. Mou, J. Takayasu, H. Tokuda, and H. Nishino. 2000. Inhibitory effect of flavonoids from Citrus plants on Epstein-Barr virus activation and two-stage carcinogenesis of skin tumors. Cancer Lett. 154:101-105.

Kato-Noguchi, H., Y. Tanaka, T. Murakami, S. Yamamura, and S. Fujihara. 2002. Isolation and identification of an allelopathic substance from peel of Citrus junos. Phytochemistry 61:849-853.

Ogata, S., Y. Miyake, K. Yamamoto, K. Okumura, and H. Taguchi. 2000. Apoptosis induced by the flavonoid from lemon fruit (Citrus limon BURM. f.) and its metabolites in HL-60 cells. Biosci. Biotechnol. Biochem. 64:10751078.

Putnam, A.R. 1988. Allelochemicals from plants as herbicides. Weed Technol. 2:510-518.

Seigler, D.S. 1996. Chemistry and mechanisms of allelopathic interactions. Agron. J. 88:876885.

Shilling, D.G., J.A. Dusky, M.A. Mossler, and T.A. Bewick. 1992. Allelopathic potential of celery residues on lettuce. J. Amer. Soc. Hort. Sci. 117:308-312.

Uchiyama, S., T. Sumida, and M. Yamaguchi. 2004. Anabolic effect of beta-cryptoxanthin on bone components in the femoral tissues of aged rats in vivo and in vitro. J. Health Sci. 50:491-496.

Weston, L.A. 1996. Utilization of allelopathy for weed management in agroecosystems. Agron. J. 88:860-866. 